\title{
Plutonium Speciation, Solubilization, and Migration in Soils
}

Project Number: 73819 Annual Report, 6/19/01

Principal Investigator: Mary P. Neu, Mail Stop G739, Los Alamos National Laboratory (LANL), Los Alamos, NM 87544, (505) 667-9313, mneu@lanl.gov

Other Investigators: Donna M. Smith, Wolfgang Runde, Matt Ginder-Vogle, LANL Lynne Soderholm and S. Skanthakumar, Argonne National Laboratory (ANL)

Graduate Student: Matt Ginder-Vogle, B.S. in Chemistry from Carleton College, 12/00; attending Ph.D program in geochemistry at Stanford University beginning 8/01.

\section{Research Objective:}

The DOE is currently conducting cleanup activities at its nuclear weapons development sites, many of which have accumulated plutonium $(\mathrm{Pu})$ in soils for 50 years. To properly control Pu migration in soils within Federal sites and onto public lands, better evaluate the public risk, and design effective remediation strategies, a fundamental understanding of $\mathrm{Pu}$ speciation and environmental transport is needed. This type of information is increasingly important as the remediation and decommissioning plans for actinide-contaminated sites includes in situ stabilization or clean-up to a particular level of residual contamination. Long-term stewardship of the sites and return of these sites to public use will require more accurate predictions of contamination stability and mobility than is possible using current information.

The key scientific goals of this project are: to determine Pu concentrations and speciation at contaminated DOE sites; to study the formation, stability, and structural and spectroscopic features of environmentally relevant Pu species; to determine the mechanism(s) of interaction between $\mathrm{Pu}$ and $\mathrm{Mn} / \mathrm{Fe}$ minerals and the potential release of Pu via redox cycling; and to model the environmental behavior of plutonium. Our goal is to use characterization, thermodynamic, mineral interaction, and mobility data to develop better models of radionuclide transport and risk assessment, and to enable the development of science-based decontamination and stewardship stategies.

This research will fill important gaps between fundamental actinide science and the problems impeding site clean-up, plutonium disposition, and accurate risk assessment. Information gained will allow for the development of technologies and clean-up approaches targeting particular plutonium contaminants and improved assessment of risks associated with actinide migration, site remediation, and decontamination. By combining very specific study of plutonium at well-characterized contaminated sites, with laboratory studies on the most important plutonium and mineral component systems, 
we will provide essential knowledge of contaminant characteristics and distinguish critical geochemical processes and mechanisms. Because we are obtaining plutonium speciation information from real sites and significantly advancing of environmentally important systems, our research will also enable defensible long-term stewardship of DOE sites. 


\section{Research Progress and Implications:}

This report summarizes work performed in the first year of a three-year project. In this year we are focusing on the following: 1) the interactions between plutonium compounds and redox active iron and manganese minerals, 2) the interactions between plutonium compounds and sediments from the Hanford site, 3) fundamental studies of plutonium complexes that are relevant to the environment and are important for geochemical modeling, 4) characterization of plutonium in samples from contaminated sites, and 5) site-specific geochemical modeling. In the following sections our most important results will be briefly summarized. Additional details are available in the attachments and by contacting the principal investigator.

Interactions between $\mathrm{Pu}$ compounds and redox active iron and manganese minerals. Our most important results thus far this fiscal year come from our study of the interactions of $\mathrm{Pu}$ species with the synthetic mineral $\mathrm{MnO}_{2}$. Delta- $\mathrm{MnO}_{2}$ (sometimes referred to as synthetic birnessite and hydrous manganese dioxide) is one of the most common forms of mineralized manganese in soils and is believed to be the form of $\mathrm{MnO}_{2}$ precipitated out of groundwater during redox cycling. In addition to being prevalent, this mineral generally has high surface area, large metal ion sorption capacity, and a very reactive and redox active surface. Mn-based minerals are common in coatings found on other minerals and are therefore predicted to be significant 'sink' for contaminant metals, especially for 'hard', redox active metals like the actinides. We have designed an experimental plan to determine how $\mathrm{MnO}_{2}$ and other manganese-based phases affect the oxidation state and speciation of plutonium in solution, how much plutonium these phases take up, how the behavior of plutonium differs from uranium and neptunium in these systems, and how fast the actinides are sorbed.

We have found that under all of the conditions we have studied (varying $\mathrm{pH},[\mathrm{Pu}]$, $\mathrm{Mn} / \mathrm{Pu}$ ratio, ionic strength, time, etc.) $\mathrm{Pu}(\mathrm{V})$ is oxidized to $\mathrm{Pu}(\mathrm{VI})$ in the mineral contact and sorption process(es). Even several forms of $\mathrm{Pu}(\mathrm{IV})$ are oxidized by this mineral. By studying both the solution speciation and the form of $\mathrm{Pu}$ that is sorbed onto the mineral, we have shown that the $\mathrm{Pu}$ is in the oxidized form in both the solution and solid states. Representative X-ray absorbance (XAS) spectra of the $\mathrm{MnO}_{2}$ after Pu sorption are shown in Figure 1 and optical absorbance spectra of the solution phase are shown in Figure 2. The details of this study along with all of the other characterization data, sorption rates and sorption capacity can be found in the paper currently being reviewed for publication in Environmental Science and Technology. 


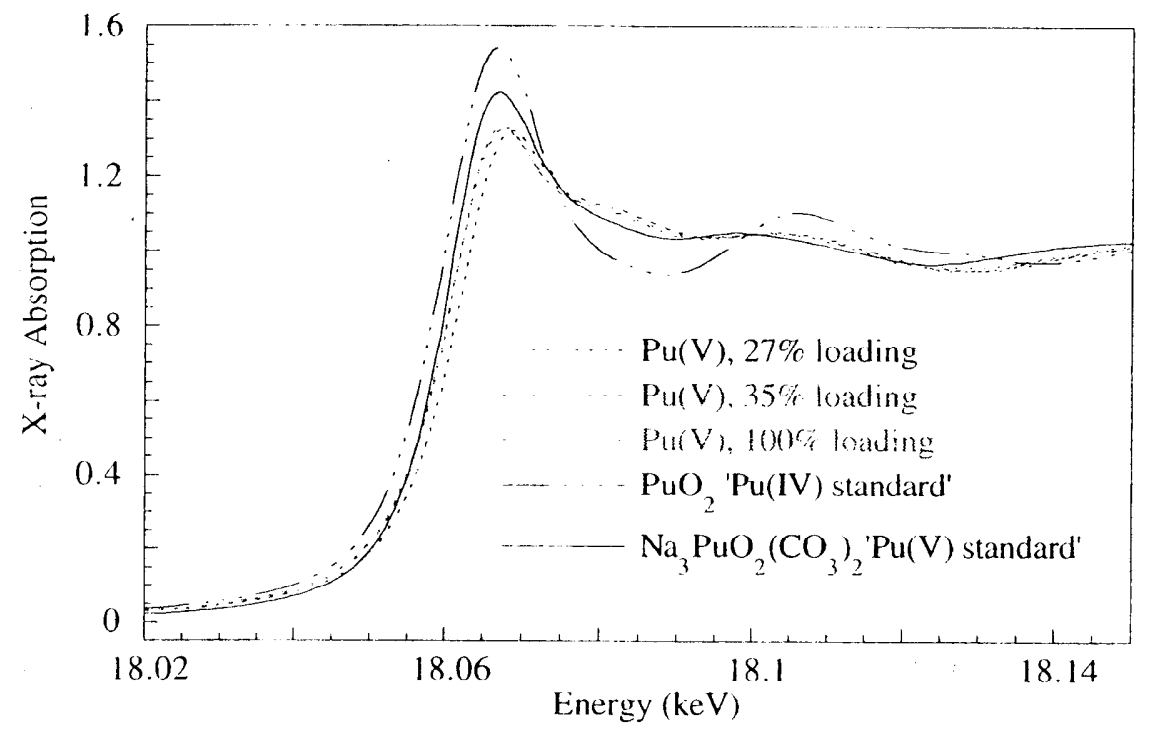

Figure 1. X-ray absorbance spectra of $\mathrm{MnO}_{2}$ after $\mathrm{Pu}(\mathrm{V})$ sorption.

Absorption edge energies and near-edge features clearly show the Pu associated with the mineral is in the +VI oxidation state.

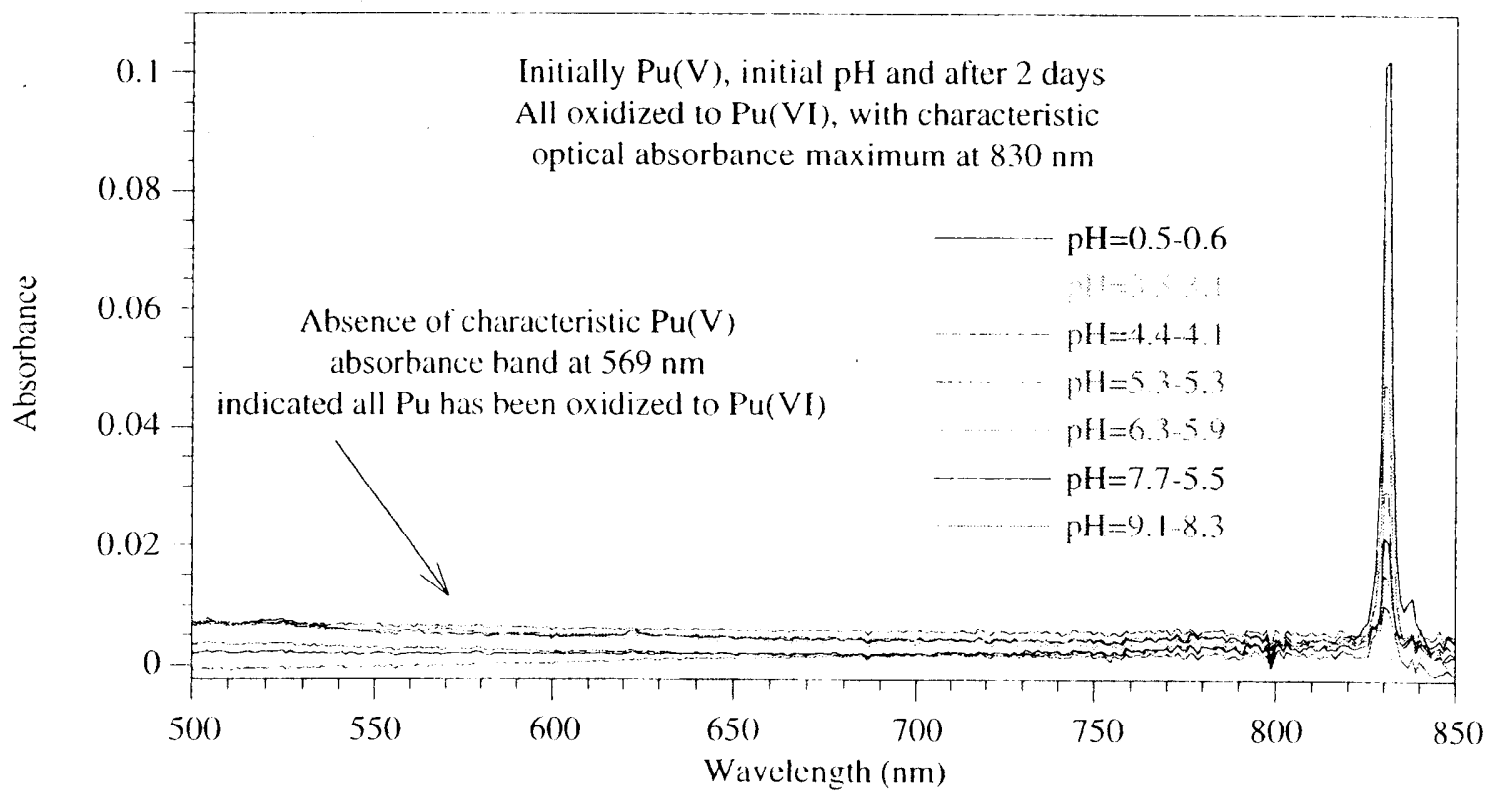

Figure 2. Optical absorbance spectra of the solution phase in equilibrium with $\mathrm{MnO}_{2}$ during $\mathrm{Pu}$ sorption.

Each spectrum is for a different experiment with a different solution $\mathrm{pH}$ Initial $\{\mathrm{Pu}\}$ and $\mathrm{Pu} / \mathrm{MnO}]_{2}$ ratio were very similar. 
These research results are noteworthy because heretofore it was thought that $\mathrm{Pu}$ in the $+V$ oxidation state would be reduced to the $+I V$ oxidation state upon interaction with minerals. This was a reasonable prediction based upon the expected thermodynamic stability and strong chemical bonds of surface bound $\mathrm{Pu}(\mathrm{IV})$ species and based upon the experimental results observed for other minerals such as silica and iron oxides. The oxidation of $\mathrm{Pu}(\mathrm{V})$ to $\mathrm{Pu}(\mathrm{VI})$ is important because the fraction of $\mathrm{Pu}$ that is soluble in the environment is most likely to be $\mathrm{Pu}(\mathrm{V})$ and were it to be reduced and sorbed as $\mathrm{Pu}(\mathrm{IV})$ the resulting species would be stable and the Pu would essentially be removed from solution and immobilized. However, oxidation and sorption to $\mathrm{Pu}$ (VI) does not stabilize the $\mathrm{Pu}$ as much and the Pu could then be more susceptible to chemical or other transformations. The oxidation of $\mathrm{Pu}(\mathrm{IV})$ species is more surprising. In particular, we observed the partial oxidation of colloidal $\mathrm{Pu}(\mathrm{IV})$ hydroxide, which is known to be a very stable form thermodynamically. Interestingly, the nitrilotriacetic acid (NTA) complex of Pu(IV) was not oxidized by the mineral, but was sorbed as the complex and retained the +IV oxidation state. This suggests that Pu complexed by strong anthropogenic and biogenic chelators will generally remain in the +IV state. In addition to measuring the redox changes, we determined the sorption rates, speciation changes, speciation as a function of loading, and total binding for a number of Pu species.

To put the sorption capacity and distribution constants ( $\mathrm{K}_{\mathrm{d}}$ values) for $\mathrm{Pu}$ into a larger context, the cation capacity of the $\mathrm{MnO}_{2}$ for $\mathrm{Cu}$ (II) was determined to be 0.2 moles $\mathrm{Cu}$ (II) per mole $\mathrm{MnO}_{2}$. In comparison, Pu cation capacity is approximately 0.018 moles $\mathrm{Pu}$ per mole $\mathrm{MnO}_{2} . \mathrm{K}_{\mathrm{d}}$ values were determined and then normalized to account for the different $\mathrm{MnO}_{2}$ concentrations in solution. Below the maximum surface capacity of $\mathrm{Pu}$, $>80 \%$ of plutonium is sorbed in the first 5 minutes. After one hour $>97 \%$ of plutonium is sorbed with the reaction reaching a steady state within four days. For $\mathrm{pH}<8$, both scanning electron microscopy (SEM) and XAS data suggest the Pu species on the surface is chemi-sorbed (not precipitated) to the $\mathrm{MnO}_{2}$. We believe the mechanism proceeds by oxidation of $\mathrm{Pu}(\mathrm{V})$ to $\mathrm{Pu}(\mathrm{VI})$ in solution followed by concomitant sorption to the surface. We have also begun to study the sorption of U(VI) onto $\mathrm{MnO}_{2}$. We have found that the binding capacity of $\mathrm{MnO}_{2}$ to for $\mathrm{U}(\mathrm{VI})$ is .03mmoles $\mathrm{U}(\mathrm{VI}) / \mathrm{mmole} \mathrm{MnO}_{2}$ at $\mathrm{pH}$. 6.5 . The X-ray diffraction (XRD) pattern of $\mathrm{MnO}_{2}$ contains four broad diffraction peaks at $\mathrm{d}$ spacings of $7.24,3.65,2.43,1.41 \AA$. XRD of $\mathrm{MnO}_{2}$ with $1 / 3$ capacity of U(VI) sorbed, shows no marked change from the XRD of $\mathrm{MnO}_{2}$. SEM of this same material show that the sorbed uranyl is not localized, suggesting that the $U$ interacts with the mineral at this $\mathrm{pH}$ through sorption and not surface precipitation (as Pu(VI) does). It is important to note that the XRD powder pattern of the synthetic $\mathrm{MnO}_{2}$ before and after $\mathrm{Cu}$ (II) sorption are different in that the original diffraction line at $3.65 \AA$ shifts to $4.91 \AA$. These data suggest that $\mathrm{Cu} 2+$ is sorbed onto different (presumably additional) sites than to which 
$\mathrm{UO}_{2}{ }^{2+}$ is sorbed. This is supported by the different sorption capacities for $\mathrm{Cu}(\mathrm{II}), \mathrm{U}(\mathrm{VI})$ and $\mathrm{Pu}(\mathrm{VI})$, which are approximately $0.20,0.03$, and $0.018 \mathrm{mmol}$ sorbing metal per mmol mineral, respectively. We have performed dozens of additional actinide- $\mathrm{MnO}_{2}$ sorption experiments and are currently analyzing all of the data.

Interactions between plutonium compounds and sediments from the Hanford site. To take the next step towards understanding how the sorption of plutonium species onto minerals is related to the speciation and mobility of plutonium in the environment, we have obtained sediments from the Hanford site and have begun actinide sorption studies on these minerals. These studies can help us bridge the gap between laboratory studies, such as the sorption of $\mathrm{Pu}$ onto $\mathrm{MnO}_{2}$, and the measured and estimated environmental concentrations and distributions. The sediments we are studying are key both because they are from an actinide-contaminated site and because they contain manganese and iron oxides/oxyhydroxides as coatings on silicates. So we will be able to determine the extent to which the very minor Fe and $\mathrm{Mn}$ fraction affects the total actinide sorption. In our first sets of experiments $\mathrm{Pu}(\mathrm{V})$ and $\mathrm{Pu}(\mathrm{VI})$ were sorbed onto the sediments from solutions of approximately $10^{-4} \mathrm{M}$ and $10^{-7} \mathrm{M}$ Pu at neutral $\mathrm{pH}$. Our preliminary results suggest that $\mathrm{Pu}(\mathrm{V})$ in solution is only partially oxidized by the sediments. After days of contact time, the ratio of $\mathrm{Pu}(\mathrm{V})$ to $\mathrm{Pu}(\mathrm{VI})$ is approximately 10:1. Solutions are being analyzed using LSC to determine the concentration of actinide remaining in solution and using $\mathrm{UV} / \mathrm{vis}$ to determine the oxidation state and potentially exact form of actinide remaining in solution. Solids are being analyzed by SEM to study the morphology for the materials prior to and after sorption and to study the localization of the actinide and by EDS in attempt to determine preferential sorption to particular grains or coatings. In addition, in collaboration with Lynne Soderholm at Argonne National Lab, we will also measure the XAS spectra of the solids to determine the oxidation state of the actinide as sorbed onto the sediments and to determine the exact nature of the speciation and sorption mechanism. The data collection and data analysis are on-going.

Fundamental studies of plutonium complexes that are relevant to the environment and important for geochemical modeling. Using support from this program and from a distinct program funded by basic energy sciences, we are preparing and studying aqueous coordination complexes of plutonium and other actinides. Of the compounds we have characterized in the last year the most environmentally relevant is the aquo complex of $\mathrm{Pu}(\mathrm{III})$. To prepare the compound plutonium metal was dissolved in triflic acid and the resultant solution was concentrated down to yield large blue crystals suitable to singlecrystal X-ray analysis. The crystals are isotypic to the lanthanide triflates, crystallizing in the hexagonal space group $\mathrm{P} 6 / \mathrm{m}$ with $\mathrm{a}=13.9283(6)$ and $\mathrm{b}=7.3816(4) \AA$. The plutonium(III) is coordinated by nine water molecules arranged in an ideal tricapped, trigonal-prismatic (TCTP) geometry (Figure 3). The two unique plutonium aquo bond 
distances are to $\mathrm{O}(1), 2.574(3) \AA$ (capping) and $\mathrm{O}(2), 2.476(2) \AA$ (prismatic). The weighted average of the plutonium to water distances of $2.51 \AA$ compares very well to those reported in two previously published separate EXAFS studies of plutonium(III) in dilute chloride solutions of 2.51 and $2.49 \AA$. The plutonium to water distance is, as expected, longer than those within a plutonium(IV) complex.

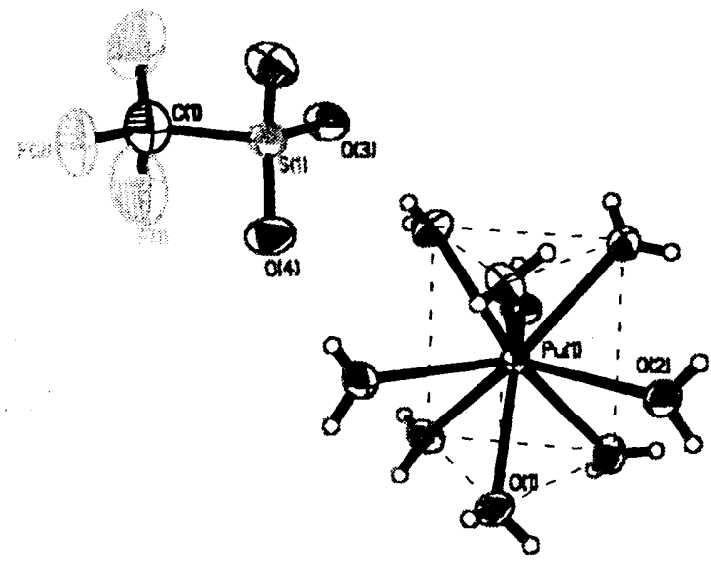

Figure 3. Thermal ellipsoid plot (40\%) of $\left[\mathrm{Pu}\left(\mathrm{H}_{2} \mathrm{O}\right)_{4}\right]\left[\mathrm{CF}_{3} \mathrm{SO}_{3}\right]_{3}$.

This single crystal $\mathrm{X}$-ray structure verifies the nona-coordinate plutonium(III) ion in the solid state. To infer the hydration number of plutonium(III) in solution we measured the solid-state diffuse reflectance spectrum of ground single crystals and compared it with the solution UV/vis/NIR spectrum of plutonium(III) in triflic acid. The spectra suggest similar or identical chromophores in the solution and the solid states, supporting the conclusion that plutonium(III) in aqueous acidic solutions is predominantly nine coordinate. This compound is important becausc it is the first single crystal X-ray discrete molecular structure containing plutonium(III) and also because it conclusively shows the coordination environment of $\mathrm{Pu}(\mathrm{III})$ in aqueous solution.

Characterization of plutonium in samples from contaminated sites and Site-specific geochemical modeling. Samples from the Hanford site are being screened and thus far none have been found that are suitable for our analysis. We are in contact with the site and have made arrangements to receive these samples when they have been collected and become available. We have an active beamline proposal at the Advanced Photon Source to allow for X-ray absorbance measurement of these samples. Geochemical modeling has not been emphasized in this fical year. Our experimental work has been extensive, and that in addition to writing manuscripts and reports has required all of our available resources.

\section{Planned Activities:}

Our major effort for the remainder of this fiscal year will be continuing to study the sorption of actinide species onto synthetic minerals, mixed minerals, and sediments as 
described above. We will write and submit another beamtime request proposal to the Advanced Photon Source to continue this work and to ensure we will be able to characterize real samples from the Hanford site should they become available. We have manuscripts in preparation or planning in all of the areas of this research project, those which we should be able to submit before the end of the year are: 1. The Speciation and Localization of Plutonium in Samples from the RFETS 2. The Sorption of $\mathrm{Cu}$ (II) onto Manganese Dioxide and 3. Structure and Stability Studies of Colloidal Plutonium(IV) Hydroxide.

\section{Information Access:}

Publications:

1. The publication, "Interactions of $\mathrm{Pu}(\mathrm{V})$ and $\mathrm{Pu}(\mathrm{VI})$ with Manganese Dioxide, (LAUR-01-1877) has been submitted for publication in Environmental Science and Technology and is included as an appendix to this report.

2. The publication "High-Yield Synthesis and Single Crystal X-ray Structure of a Plutonium(III) Aquo Complex: $\left[\mathrm{Pu}\left(\mathrm{H}_{2} \mathrm{O}\right)_{9}\right]\left[\mathrm{CF}_{3} \mathrm{SO}_{3}\right]_{3}$." has been accepted for publication in Inorganic Chemistry and is included as an appendix to this report.

Presentations (Abstracts for some of these presentations are given below):

1. Mary Neu gave an invited talk at the EMSP Vadose Zone Principal Investigtor Workshop at PNNL, November 28-30, 2000.

2. Mary Neu and Donna Smith gave two oral presentations including the results of this project at the International PacifiChemistry Conference December, 14-19, 2000.

3. Mary Neu will give a plenary lecture on this project, entitled, "Plutonium Speciation and Mobility in Environmental Systems," at the EMSP symposium at the Fall 2001 American Chemical Society National Meeting in Chicago, August 28, 2001.

4. Donna Smith will give an oral presentation, entitled, " "'as part of the EMSP symposium at the Fall 2001 American Chemical Society National Meeting in Chicago, August 28, 2001.

5. Matt Ginder-Vogle will give an oral presentation, entitled, " "as part of the EMSP symposium at the Fall 2001 American Chemical Society National Meeting in Chicago, August 28, 2001.

6. Mary Neu will present research on this project as part of an oral presentation at the $8^{\text {th }}$ International Conference on Radionuclide Migration in the Geosphere to be held in September, 2001 in Bregenz, Austria. This conference is held every two years with the host nation alternating between Europe, Japan, and the United States.

7. Mary Neu will present a seminar on research results from this project as part of a site visit to the Institut für Kernchemie, Universität Mainz, Germany, September, 2001. 
8. Mary Neu will present a seminar on research results from this project as part of a site visit to the Centre for Energie Atomic, Saclay Laboratories, September, 2001.

9. Mary Neu will present research on this project as part of an invited oral presentation at the Actinides'01 Conference to be held in Hayama, Japan in November, 2001. This international conference is held every four years with the host nation alternating between Europe, Japan, and the United States.

Proposals:

The proposal we wrote to request beamtime at the Advanced photon source is available upon request.

\section{Abstract for Presentation 3:}

"Plutonium Speciation and Mobility in Environmental Systems"

As part of the Environmental Management Science Program, we are investigating the factors that influence the speciation and migration of plutonium in groundwaters and soils. Our approach is to perform a broad range of chemistry, geochemistry, biogeochemistry, themodynamic modeling, and characterization studies in attempt to better access the immediate and long-term behavior of this problematic contaminant. The specific systems we have focused on include: pure aquo, hydroxide, carbonate, and chloride Pu species; interactions between these species and redox-active transition metal minerals; Pu-contaminated soils from the RFETS and sediments from the Hanford site; and development of a thermodynamic database to generate predominance diagrams for site-specific conditions. To study individual systems we utilize a range of classical and advanced techniques, from potentiometric and spectrophotometric titrations to singlecrystal X-ray diffraction, electron microscopy, and X-ray absorbance spectroscopy. Details of our most important findings on key systems and a summary of our program will be presented.

\section{Abstract for Presentation 4:}

"Interactions of Plutonium with Manganese Dioxide and Manganese-Containing Sediments"

It is important to understand the influence of redox active materials on plutonium speciation because ions sorbed to particles, mineral coatings or minerals may exhibit different mobility in the environment as compared to plutonium that exists as ions or complexes in solution. We are determining the sorption kinetics, oxidation state changes, speciation as a function of surface coverage, and sorption capacity of $\mathrm{MnO}_{2}$ and $\mathrm{Mn}$ containing sediments that have been equilibrated with $\mathrm{Pu}$ (IV), (V), and (VI) solutions. Plutonium solution concentrations and oxidation states are determined using liquid scintillation counting (LSC) and UV-Vis spectroscopy while species distribution and 
composition on solid samples are studied using diffuse reflectance spectroscopy, scanning electron microscopy (SEM) and X-ray adsorption spectroscopy (XAS). Pu $\mathrm{L}_{3}$ edge X-ray absorption spectroscopy (XAS) has been used to determine directly the oxidation state and coordination environment of Pu adsorbed to the mineral surface.

\section{Abstract for Presentation 5: \\ "Actinyl Interaction with Iron and Manganese Oxides and (oxy)Hydroxides Under Abiotic and Biotic Conditions"}

Redox-active metal mineral phases and surface coatings may strongly affect the environmental behavior of redox sensitive contaminant metals. To evaluate the effects of iron and manganese oxides and (oxy)hydroxides on the solubility and speciation of actinides, we are studying the interactions of several actinyl species (U(VI), $N p(V)$, $\mathrm{Pu}(\mathrm{VI})$ and $\mathrm{Pu}(\mathrm{V})$ ) with synthctic birnesitte and goethite and $\mathrm{Fe}$ - and $\mathrm{Mn}$-containing sediments. We have performed a number ofsorption experiments within these systems, considering sorption kinetics, oxidation state changes, speciation, and total binding. In addition to performing a broad range of geochemical experiments, we are investigating the effects of bacteria on these already complex mixtures. We have begun by studying the dissolution of pure and actinide-sorbed minerals by a Pscudomonas species and comparing with the corresponding abiotic dissolution. Selected data from this broad range of experiments, including spectroscopic characterization, sorption isotherms and dissolution experiments will be presented. 